\title{
WHO BENEFIT FROM WHAT MEDIA? EXAMINING KNOWLEDGE GAP HYPOTHESIS ON ENVIRONMENTAL KNOWLEDGE IN ChINA
}

\author{
Pengya Ai, Kanni Huang, Wu Li \\ (School of Media and Communication, Shanghai Jiao Tong University)
}

\begin{abstract}
Environmental knowledge inequality is a barrier to address environmental issues. This study explores the role of media use in environmental knowledge gap in China, and the empirical evidence is analyzed by using the secondary data from Chinese General Social Survey. OLS regression and heterogeneity analysis revealed that internet use increases environmental knowledge gap; radio use reduces environmental knowledge gap between people with higher and lower levels of education. Newspaper and television use have limited influence on environmental knowledge acquisition. However, newspapers and television are more beneficial for people with lower levels of education, but not those with higher levels.
\end{abstract}

Key words: Environmental knowledge, Knowledge gap hypothesis, Secondary Data, Heterogeneity analysis 


\section{INTRODUCTION}

Environmental issues have become an urgent agenda, and public participation to protect environment is a common goal around the world. Knowledge is widely acknowledged to be a crucial precondition of behavioral change, so as pro-environmental behavior (Frick et.al., 2004). Environmental knowledge refers to person's general knowledge on facts, concepts, and relationships about natural environment and ecosystems (Fryxell \& Lo, 2003). It helps individuals to better understand our environments, influences individuals' decision-making, plays an important role in addressing environmental issues (Eden, 1998; Vicente-Molina et.al., 2013). Till now, a certain number of researches has demonstrated that environmental knowledge can translate to pro-environmental behavior (Robelia \& Murphy, 2012; Carmi et.al., 2015; Cheng \& Wu, 2015), As a result, investigating factors related to people's environmental knowledge would be beneficial in order to address environmental issues.

Media are capable of informing public, and were found to have positive influence on knowledge gaining (Culbertson \& STEMPEL III, 1986; Bessinger er.al., 2004; Nguyen et.al., 2015). In general, it's difficult for laypersons to learn environmental issues (e.g. climate change) from direct observations or experience, and consequently media representation on environmental issues plays a significant role in communicating environmental risks to general population (Yang \& Ho, 2017). Just as Hansen (2011) stated, almost all what we learn and know about "the environment" are from media, including beliefs, perceptions, viewpoints, values, and knowledge.

Despite the vital role of media in facilitate individuals' knowledge gaining, different population segments benefit from media unequally due to different socioeconomic status (SES), which is known as the knowledge gap hypothesis. This hypothesis may also explain the extent to which gaining environmental knowledge through media use depends on the SES. For example, Boykoff (2011) suggested that SES variables may limit media's effects on communicating climate change issues.

Since sustainable development is also a collective effort, not only limited to individuals (Aldy et.al., 2001), increasing inequality in environmental knowledge may leads to more free-rider effects, and dampen individuals' motivation to engage in pro-environmental activities. Thus, it is worthy to gain a better understanding on the issue of environmental knowledge gap.

Unfortunately, though plenty of studies has investigated knowledge gap hypothesis across various topics (e.g. health knowledge, scientific knowledge, political knowledge, etc.), environmental knowledge is scarcely concerned by researchers on this hypothesis. Moreover, researchers have suggested that media and knowledge gap relationship vary by different topics (Gaziano, 1983). As a consequence, it becomes more difficult to speculate what environmental knowledge gap would like, let alone to form some effective strategies to prevent it.

Taken together, this study attempts to investigate the knowledge gap hypothesis on environmental knowledge. Specifically, this study aims to examine how different types of media use relates to individuals' environmental knowledge gaining among different SES populations. Based on a large national representative sample in China, this study adds new evidence on knowledge gap hypothesis in the context of environmental knowledge in China. 


\section{LITERATURE REVIEW}

\subsection{EDUCATION AND ENVIRONMENTAL KNOWLEDGE}

Education is directly associated with individual's knowledge. Generally speaking, the more formal education one has received, the more knowledge one possesses. As for environmental knowledge, education is also indicated as the first factor that predict individuals' environmental knowledge (Laurian, 2003). Knowledge gap hypothesis assumes knowledge acquisition differs among different SES, which typically be operationalized by formal education in previous studies. As for environmental knowledge, it was also well documented that education is one of the most essential variables related to environmental knowledge acquisition (Alp et.al., 2006; Zsóka et.al., 2013).

According to previous literature, people with higher levels of education possess more knowledge (Gaziano ,1983; Viswanath \& Finnegan, 1996). Additionally, meta-analysis conducted by Hwang and Jeong (2009) reported the positive relationship between education and knowledge, and the average effect size was $r$ $=0.28$. A most recent meta-analysis which analyzed knowledge gap literature from 1966 to 2018 also found a significant positive education-knowledge relationship, the overall average effect size was $r=0.26$ (Lind \& Boomgaarden, 2019). We argue that the relationship between formal education and various types of knowledge can also be applied to environmentally related knowledge. Therefore, we pose a hypothesis below.

\section{H1: The higher the levels of formal education, the higher a person scores in environmental knowledge.}

\subsection{MEDIA USE AND ENVIRONMENTAL KNOWLEDGE}

Theories have suggested that media use has a close relationship with individuals' knowledge acquisition. For instance, as uses and gratifications theory suggested, one important function of media is to satisfy people's cognitive needs (Katz \& Gurevitch, 1973). Proposed by Eveland (2001), cognitive mediation model suggested that exposure to media content is associated with elaborative information processing, and the elaborative processing is the precondition of objective knowledge gaining. Thereby, intuitively, media use should positively predict one's knowledge acquisition.

Media is a major channel for individuals to gain scientific knowledge (Wage \& Schramm, 1969; Nelkin, 1987), so as environmental knowledge. Stamm (2000) indicated that communication channels (mass media and interpersonal communication) were able to make a positive contribution to individuals' understanding of environment. Laurian (2003) suggested that formal and informal information sources are the second and third factors that predicted environmental knowledge, where formal sources referred to mass media (television, radio, newspaper, etc.), and informal sources referred to interpersonal channels.

The relationship between media use and knowledge acquisition has been supported by empirical studies. For example, Brothers et.al. (1991) found television use could be an effective way in educating the public about environmental knowledge. Chan (1998) based on a sample of 1032 secondary school students in Hong Kong, found that both television news viewership and Chinese newspaper readership had a positive correlation with students' environmental knowledge, though the correlation with newspaper readership was weak. Take climate change as the case, Study of Zhao (2013) discovered that newspaper use and internet use both 
positively contributed to environmental knowledge of climate change through the analysis of 2006 General Social Survey.

Accordingly, media are quite effective in delivering environmental knowledge across different types of media and populations. Therefore, this study proposes the hypotheses below.

H2a: The more frequent use of newspaper, the higher a person scores in environmental knowledge.

H2b: The more frequent use of radio, the higher a person scores in environmental knowledge.

H2c: The more frequent use of television, the higher a person scores in environmental knowledge.

H2d: The more frequent use of Internet, the higher a person scores in environmental knowledge.

\subsection{KNOWLEDGE GAP HYPOTHESIS}

Knowledge gap hypothesis was proposed by Tichenor, Donohue, and Olien (1970), which states that "as the infusion of media information into a social system increases, segments of the population with higher socioeconomic status tend to acquire this information at a faster rate than the lower status segments, so that the gap in knowledge between these segments tends to increase rather than decrease." This hypothesis explains why the different SES population segments present different levels of knowledge from the outset (i.e. knowledge gap), and why the existing knowledge gaps have the tendency to expand as information flows into society. Additionally, from media effects perspective, the Differential Susceptibility to Media Effects Model (DSMM) suggests that media effects are moderated by various factors, including dispositional susceptibility, developmental susceptibility, and social susceptibility factors. Generally, an individual's education level parallels their cognitive ability, which is a developmental susceptibility factor under DSMM. Therefore, educational level and media use variables should interact with each other.

In the very first knowledge gap study, Techenor et al. posited that there were several factors that lead to the gap widening phenomena: the first is communication skills. Individuals with higher education have higher ability to acquire knowledge from media. The second is the amount of stored information, that is, the better people have already been informed, the more likely they will be aware of the topic the time it appears in mass media and have a better understanding of it. The third factor is related social interaction. A higher educated person will have more interpersonal contact to discuss public affair topics. The fourth reason is selective exposure, acceptance and retention, which are resulted from educational differences. The last factor lies in the fact that most scientific and public affairs information is presented by print media, and print media is more heavily consumed by higher SES individuals (Tichenor et.al., 1970).

Although some empirical studies have verified the initial knowledge gap hypothesis, many findings contradict the hypothesis (Lind, F., \& Boomgaarden, H. G., 2019). For example, Yang \& Ho (2017) found newspaper use actually decreased the knowledge gap concerning climate change understanding. They attributed this decreased effect to two factors: the ceiling effect and that climate change is categorized as a type of risk. The ceiling effect occurs when higher educated individuals already possess sufficient environmental knowledge, 
so that there is less and less novel information in media, which they haven't previously encountered. Therefore, media's marginal effects of increasing knowledge will decline. Secondly, individuals fear the threat of climate change, and might be appropriately motivated to learn about it. In so doing, they exhibit the same levels of cognitive and accessible advantages as the more highly educated. Moreover, television is found to have a narrowing effect on the knowledge gap (Yang \& Ho, 2017; Chang, et.al., 2018). This could be the result of television's less cognitively demanding nature, compared with print media. Since less cognitive skill, effort, and background knowledge are required for watching television, it may be more effective at conveying information to users, regardless of their educational level. This produces a knowledge-levelling effect.

Given these consistencies, this study reviewed previous studies according to media type.

\subsubsection{Newspaper}

Since newspaper is generally text-based media channel, it requires more cognitive capacities to process text information, which is easier for more educated people. Therefore, newspaper is likely to be more beneficial to more educated ones, and thus widening knowledge gap (Lind \& Boomgaarden, 2019). It was discovered that political knowledge gap became greater for newspaper readers in Nordic countries (Jenssen, 2013) and South Korea (Kim, 2008). Meta-analysis also demonstrated that the increasing use of print media would widen knowledge gap (Lind \& Boomgaarden, 2019).

However, as for climate change knowledge, Yang \& Ho (2017) found that the use of newspaper decrease knowledge gap. They attributed this inconsistency to ceiling effect and the nature that climate change issue is categorized as a risk. Besides, some studies didn't find newspaper use had significant effects on knowledge gap, such as political knowledge gap in the U.S. (Lu \& Douglas, 2011), factual scientific knowledge and procedural scientific knowledge (Chang et.al., 2018).

Given literature listed above, this study suggests that print media generally requires more cognitive ability, thus is more popular among higher educated ones and easier to communicate information to them. Besides, environmental knowledge is a kind of factual scientific knowledge, which is less difficult to understand and memorize for higher educated people. Therefore, this study proposes the following hypothesis:

\section{H3a: Newspaper use will widen environmental knowledge gap between high- and low-SES groups.}

\subsubsection{Radio}

In a most recent meta-analysis conducted by Lind \& Boomgaarden (2019), radio use didn't show any significant effect on knowledge gap, and it's worth noting that rarely did researchers examined the association between radio use and knowledge gap. Unlike reading, listening is instinctual for people (Hew, K. F., 2009), which requires less cognitive ability and education to understand the information (e.g. illiterates are not able to read, but they can learn through listening). Therefore, radio may be more beneficial for less educated ones when gaining information and knowledge. As a result, this study posits the following hypothesis:

H3b: Radio use will narrow environmental knowledge gap between high- and low-SES groups.

\subsubsection{Television}


Compared to print media, television is not that cognitively demanding, and requires less cognitive skill, effort, and background knowledge. Therefore, television maybe more effective in conveying information to users regardless of educational level, and resulting in a knowledge-leveling effect, which is opposite from initial knowledge gap hypothesis (Yang \& Ho, 2017; Chang et.al., 2018; Lind \& Boomgaarden, 2019). As for political knowledge, Kwak (1999) found television news viewing significantly reduced the political knowledge gap between education groups, and Jenssen (2013) had found similar results in Nordic countries. Yang \& Ho (2017) found television could narrow the climate change knowledge gap. Chang et.al. (2018) found television narrowed the procedural scientific knowledge gap, but didn't exert significant effects on factual scientific knowledge gap.

However, television's influence wasn't found in both the study of Kim (2008) in South Korea and the study of Lu \& Douglas (2011). Meta-analysis found television use had no significant effect on knowledge gap (Lind \& Boomgaarden, 2019).

Accordingly, most studies supported the narrowing effect of television use to knowledge gap. Given that television offers a more entertaining form of information (video and audio) for audience (Su, et.al., 2014), and that television viewing is less demanding to audiences' ability comparing with merely reading, this study predicts the relationship as following hypothesis.

\section{H3c: Television use will narrow environmental knowledge gap between high- and low-SES groups.}

\subsubsection{Internet}

Most studies presented that internet augmented knowledge gap. One explanation is selective exposure. Lu \& Douglas (2011) suggested that internet provides more personalized content choices than traditional media do. Traditional media offer rather homogeneous content, while internet is specifically heterogeneous and potentially unlimited. Therefore, they proposed that "the association between selective exposure and education is diluted by the nature of old media" but augmented by the internet. Based on 2008-2009 American National Election Studies data, they found the use of internet widened the political knowledge gap, ever more than traditional media did. This finding was consistent in South Korea (Kim, 2008) and the meta-analysis study.

Additionally, the lack of motivation and information-seeking skills might lead to the augmentation of existing knowledge gap (Lu \& Douglas, 2011). Online readers appear to read less international and political news, and were less likely to recall the information exposed (Tewksbury \& Althaus, 2000). More educated people may have more capacity and motivation to learn more information about public affairs. Besides, effective internet use requires more active and skilled users (Hargittai \& Hinnant, 2008). Thus, better educated individuals are more capable of using internet to gain knowledge, and therefore the internet use increases knowledge gap.

the above conclusions are not always supported by empirical findings. For instance, while Chang et.al. (2018) found that reading online newspapers widened procedural scientific knowledge gap, but did not widen factual scientific knowledge.

From the review above, most studies supported that internet use widens knowledge gap due to cognitive demand and selective exposure. Therefore, this study expects the following relationship. 
H3d: Internet use will widen environmental knowledge gap between high- and low-SES groups.

\section{MeTHOD}

\subsection{SAMPLE}

The secondary data were collected from the Chinese General Social Survey (CGSS). CGSS is a national representative survey conducted since 2003, covering both rural and urban population in 31 provinces in mainland China. CGSS employs a multi-stage stratified random sampling method. Since not all variables in different waves of CGSS is exactly the same, we selected 2010 CGSS and 2013 CGSS to maintain consistency and to serve our research purposes. After data cleaning, a sample of 11,626 respondents were kept for this study.

Control variables include gender ( $1=$ male, $0=$ female; $54.20 \%$ male $)$, age $(\mathrm{M}=46.754, \mathrm{SD}=15.567)$, annual income ( $\mathrm{M}=25817.90, \mathrm{SD}=46736.49$; $\log$ (income) was included in later OLS estimation models), member of Chinese Communist Party or not (abbreviated to party member, $1=$ party member, $0=$ not party member; $12.54 \%$ party member $)$, agricultural hukou or not $(1=$ agricultural hukou, $0=$ not agricultural hukou; $52.19 \%$ agricultural hukou), ethnicity ( $1=$ Han, $0=$ other ethnics; $91.55 \%$ Han ethnics), year fixed effect ( $1=$ the year $2013,0=$ the year $2010,76.88 \%$ the year 2013)

\subsection{MEASURES}

\subsubsection{Education}

Education was recoded to the years of formal education in China's education system. After recoding, the levels of education are transformed into corresponding years of education $(0=$ below primary education, $11.20 \% ; 6=$ primary school education or old-style private school, $22.77 \% ; 9=$ junior high school, $30.15 \% ; 12=$ senior high school, $19.28 \% ; 15=$ college, $8.69 \% ; 16=$ university, $7.21 \% ; 18=$ graduates, $0.71 \% . \mathrm{M}=8.977, \mathrm{SD}=4.483$ ). The education distribution was substantially in line with the results of the sixth national population census of China in 2010, demonstrating the representativeness of the sample.

\subsubsection{Media use variables}

Media use was measured by a set of single item questions asking how often $(1=$ never, $2=$ hardly, $3=$ sometimes, 4 = usually, 5 = always) respondents use (a)newspaper, (b)radio, (c)television and (d)internet (including mobile phone) in the past year. Additionally, in order to better interpret the estimated coefficients of OLS model, also for robustness check, above 4 types of media use were additionally recoded as 4 dummy variables $(1=$ use, $0=$ never use $)$.

Table 1 showed the descriptive statistics of the above 4 types of media use.

Table 1 Descriptive statistics of media use variables 


\begin{tabular}{lcccccc}
\hline & \multicolumn{2}{c}{ Total } & \multicolumn{2}{c}{$\mathbf{2 0 1 0}$} & \multicolumn{2}{c}{$\mathbf{2 0 1 3}$} \\
\hline Mean & Std. Dev. & Mean & Std. Dev. & Mean & Std. Dev. \\
\hline Newspaper & 2.211 & 1.281 & 2.389 & 1.357 & 2.157 & 1.252 \\
Radio & 1.890 & 1.162 & 1.876 & 1.190 & 1.894 & 1.153 \\
Television & 4.145 & 0.938 & 4.189 & 0.916 & 4.132 & 0.945 \\
Internet & 2.126 & 1.521 & 1.927 & 1.417 & 2.180 & 1.547 \\
\hline
\end{tabular}

Statistics in Table 1 shows that during the year 2010-2013, television was the most frequently used media, while the other media types (newspaper, radio and internet) were not as frequently used as television.

In addition, 2010-2013 CGSS data offered a variable that helped understand the media use condition in the year of 2010 and 2013. It was an item right after the question "How often do you use the media below in the past year?" (i.e. media use measure item in this study), which asked the respondents "What type of media listed above is your uppermost information source?" Individuals would use almost all types of media for various functions (e.g. entertainment), but they would depend on some for information acquisition function. Hence, this item helped find out the main information source by types of media. The proportion of the four types of media use were calculated for each educational level (since there were some missing data and other types of media types (counted very few), the sum of proportions in each educational level was not equal to $100 \%)$.

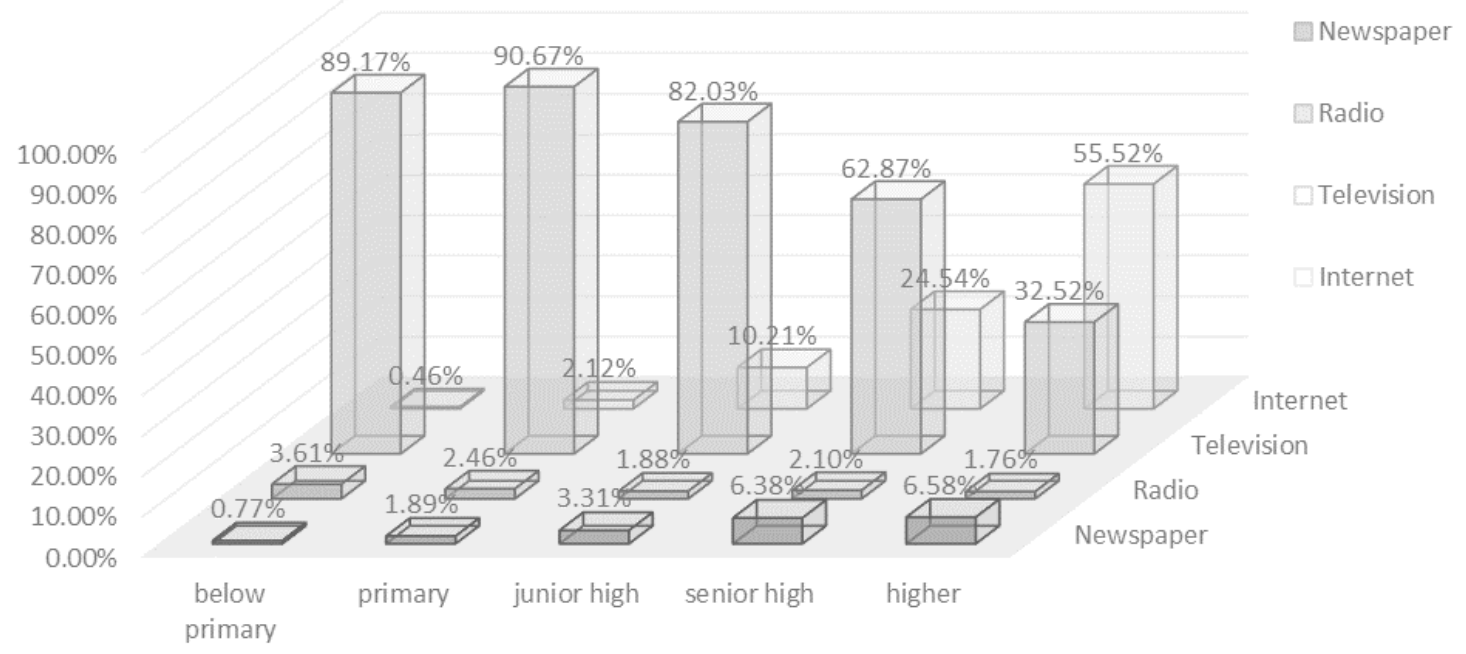

Picture 1 Uppermost information source proportion

\subsubsection{Environmental knowledge}

Environmental knowledge was measured by 10 dichotomous (true/false) items regarding environment issues: (a) Automobile exhaust will not threaten human health (false), (b) Excessive use of chemical fertilizers and pesticides is harmful to the environment (true), (c) The use of phosphorus-containing detergent will not cause water pollution (false), (d) Fluoride emissions from fluorine-containing refrigerators will damage atmospheric ozone (true), (e) The generation of acid rain has nothing to do with coal burning (false), (f) The existence of 
species is interdependent, and the disappearance of a species will cause a chain reaction (true), (g) In China's air quality report, Grade III air quality means better quality than Grade I (false), (h) A single species forest is more prone to suffer diseases and pests (true), (i) In China's water pollution report, the water quality of Category V is better than that of Category I (false), (j) Increased atmospheric carbon dioxide will cause global warming (true). Each item was recoded to 0 if the answer is wrong or "don't know", and 1 if the answer is right. The total 10 items were summed up into a single index as the measure of environmental knowledge (M $=4.868, \mathrm{SD}=2.815$ ).

\section{DATA ANALYSIS AND RESULTS}

\subsection{DESCRIPTIVE STATISTICS}

\subsection{BASELLINE RGGRESSION}

Hierarchical OLS regression analysis was applied to test the hypothesis. Model (1) only includes education as the main independent variable, other demographic variables and time fixed effect were included as control. Four types of media use were entered into Model (2) and Model (3) as media use variables, where media use in Model (3) were dummy variables (dichotomous measure of media use). Finally, interaction terms of different types of media use and education were entered into model (4) and model (5), where media use in Model (5) were dummy variables. Table 2 shows the OLS estimation results.

Table 2 Hierarchical OLS regression

\begin{tabular}{|c|c|c|c|c|c|}
\hline & (1) & (2) & (3) & (4) & (5) \\
\hline \multicolumn{6}{|l|}{ Independent variables } \\
\hline education & $0.182^{* * * *}$ & $0.136^{* * *}$ & $0.145^{* * *}$ & $0.192^{* * * *}$ & $0.184^{* * * *}$ \\
\hline Media use variables & & (ordered) & (dichotomous) & (ordered) & (dichotomous) \\
\hline newspaper & & $0.217^{* * *}$ & $0.475^{* * *}$ & $0.321^{* * *}$ & $0.396^{* *}$ \\
\hline radio & & 0.029 & 0.030 & $0.195^{* * *}$ & $0.434^{* * * *}$ \\
\hline television & & -0.001 & -0.011 & 0.069 & 0.332 \\
\hline internet & & $0.260^{* * * *}$ & $0.678^{* * * *}$ & $0.103^{+}$ & 0.009 \\
\hline \multicolumn{6}{|l|}{ Interaction terms } \\
\hline newspaper×education & & & & $-0.009^{+}$ & 0.013 \\
\hline radio $\times$ education & & & & $-0.018^{* * *}$ & $-0.045^{* * *}$ \\
\hline television $\times$ education & & & & $-0.008^{+}$ & $-0.047^{+}$ \\
\hline internet $\times$ education & & & & $0.014^{* *}$ & $0.065^{* * * *}$ \\
\hline \multicolumn{6}{|l|}{ Control variables } \\
\hline gender & $0.188^{* * *}$ & $0.185^{* * *}$ & $0.183^{* * *}$ & $0.178^{* * *}$ & $0.194^{* * *}$ \\
\hline age & $-0.020^{* * *}$ & $-0.012^{* * *}$ & $-0.011^{* * *}$ & $-0.012^{* * *}$ & $-0.011^{* * *}$ \\
\hline $\log ($ income $)$ & $0.381^{* * * *}$ & $0.294^{* * *}$ & $0.309^{* * * *}$ & $0.293^{* * *}$ & $0.313^{* * *}$ \\
\hline party member & $0.329^{* * * *}$ & $0.185^{* *}$ & $0.247^{* * * *}$ & $0.191^{* *}$ & $0.218^{* *}$ \\
\hline agriculture hukou & $-0.781^{* * * *}$ & $-0.568^{* * *}$ & $-0.612^{* * *}$ & $-0.544^{* * *}$ & $-0.582^{* * *}$ \\
\hline Han ethnics & $0.178^{*}$ & $0.135^{+}$ & $0.132^{+}$ & $0.135^{+}$ & 0.125 \\
\hline year fixed effect & $-0.519^{* * * *}$ & $-0.521^{* * *}$ & $-0.529^{* * *}$ & $-0.523^{* * *}$ & $-0.533^{* * *}$ \\
\hline
\end{tabular}




\begin{tabular}{lccccc} 
Constant & $1.012^{* * *}$ & $0.767^{* *}$ & $1.049^{* *}$ & 0.258 & $0.665^{+}$ \\
\hline R-squared & 0.307 & 0.326 & 0.322 & 0.328 & 0.324 \\
\hline
\end{tabular}

Notes: $\mathrm{N}=11,626 ;{ }^{+} \mathrm{p}<0.1,{ }^{*} \mathrm{p}<0.05,{ }^{* *} \mathrm{p}<0.01,{ }^{* * *} \mathrm{p}<0.001$

Model (1) indicated that, the higher education individuals got, the greater amount of environmental knowledge they possessed. In addition, the positive relationship remained constant across Model (2) to Model (5), therefore, H1 was supported.

In terms of media use variables, only newspaper and internet use were found to be more effective predictors on environmental knowledge, and both effects were positive. The results were consistent for both ordinallevel and nominal-level measurements in media use variables. Estimation results in Model (3) displayed that those who use newspaper got 0.475 more scores than those who didn't use newspapers, and those who use internet would get 0.678 more scores than those who didn't use internet.

However, it's dangerous to merely look into Model (2) and Model (3) to draw the conclusion that only newspaper and internet use had significant impact on environmental knowledge, while radio and television failed. As interaction terms were added to OLS models (Model (4) and (5)), the significant positive effects of newspaper still remained, and was robust for two types of media use measurement. Nevertheless, the results of the other three types of media use changed.

Radio use became a statistically significant positive predictor of environmental knowledge, the interaction term of radio use and education was also significant, especially the coefficient of the interaction term was negative. That is, the higher an individual's educational level was, the more likely radio's positive effect on environmental knowledge would diminish, even the effects will became negative among those who received high education, thus counterbalanced the positive effects amid low educational level people and finally resulted in the results of Model (2) and (3).

Internet use was no longer statistically significant after interaction items were entered, but the interaction term of internet use and education was positively related to environmental knowledge and the relationship was robust for two types of media use measurement. That is, the coefficient of internet use would increase as educational level increased. This result suggested that, the higher education one received, the more internet's impact on environmental knowledge would have.

It's worthy to mention that, at 0.1 significant level, the interaction item of television use and education had a negative effect on environmental knowledge's acquisition. Though the coefficient of television use was positive in Model (4) and (5), they are not statistically significant. That is, as people's educational level increase, the more negative impact television would have on environmental knowledge.

\subsection{HETEROGENEITY ANALYSIS}

As the OLS regression results in Table 3 seems a little bit confused to understand what exactly the relationship between education, media use and environmental knowledge, heterogeneity analysis was applied to make a detailed look into the media effects across different educational levels. Specifically, samples were split into 5 groups (below primary, primary, junior high, senior high, higher) according to education distribution, and OLS regression was used separately in each group. Table 3 is the OLS analysis results where 
media use measured as ordered variables, Table 4 also displays OLS analysis results when media use variables were dummy.

Table 3 Heterogeneity analysis (ordered measure)

\begin{tabular}{lccccc}
\hline & $\begin{array}{c}(\mathbf{6}) \\
\text { below primary }\end{array}$ & $\begin{array}{c}(\mathbf{7}) \\
\text { primary }\end{array}$ & $\begin{array}{c}(\mathbf{8}) \\
\text { junior high }\end{array}$ & $\begin{array}{c}(\mathbf{9}) \\
\text { senior high }\end{array}$ & $\begin{array}{c}(\mathbf{1 0}) \\
\text { higher }\end{array}$ \\
\hline Media use variables & & & & & \\
newspaper & $0.520^{* * *}$ & $0.239^{* * *}$ & $0.271^{* * * *}$ & $0.153^{* *}$ & $0.089^{+}$ \\
radio & $0.249^{* * *}$ & $0.086^{+}$ & 0.020 & 0.018 & $-0.103^{*}$ \\
television & 0.027 & 0.054 & $0.097^{+}$ & 0.041 & $-0.207^{* * * *}$ \\
internet & 0.201 & $0.248^{* * *}$ & $0.264^{* * *}$ & $0.232^{* * *}$ & $0.268^{* * *}$ \\
Control variables & & & & & \\
gender & 0.223 & $0.228^{* *}$ & $0.157^{+}$ & 0.094 & $0.400^{* * *}$ \\
age & $-0.018^{* *}$ & $-0.014^{* * *}$ & -0.009 & $-0.011^{*}$ & -0.001 \\
log(income) & $0.317^{* * *}$ & $0.385^{* * *}$ & $0.294^{* * *}$ & $0.223^{* * *}$ & 0.076 \\
party member & 0.461 & 0.053 & $0.339^{*}$ & $-0.052^{+}$ & $0.194^{+}$ \\
agriculture hukou & 0.039 & $-0.499^{* * *}$ & $-0.621^{* * *}$ & $-0.499^{* * *}$ & -0.244 \\
Han ethnics & 0.065 & 0.103 & $0.249^{+}$ & -0.131 & 0.210 \\
year fixed effect & $-0.540^{* * *}$ & $-0.701^{* * *}$ & $-0.599^{* * *}$ & $-0.412^{* *}$ & $-0.306^{* *}$ \\
Constant & 0.006 & 0.459 & $1.340^{*}$ & $3.406^{* * *}$ & $5.981^{* * *}$ \\
\hline Observations & 1302 & 2647 & 3505 & 2241 & 1931 \\
R-squared & 0.110 & 0.104 & 0.110 & 0.070 & 0.061 \\
\hline
\end{tabular}

Notes: ${ }^{+} \mathrm{p}<0.1,{ }^{*} \mathrm{p}<0.05,{ }^{* *} \mathrm{p}<0.01,{ }^{* * *} \mathrm{p}<0.001$

Table 4 Heterogeneity analysis (dichotomous measure)

\begin{tabular}{lccccc}
\hline & $\begin{array}{c}(\mathbf{1 1}) \\
\text { below primary }\end{array}$ & $\begin{array}{c}(\mathbf{1 2}) \\
\text { primary }\end{array}$ & $\begin{array}{c}(\mathbf{1 3}) \\
\text { junior high }\end{array}$ & $\begin{array}{c}(\mathbf{1 4}) \\
\text { senior high }\end{array}$ & $\begin{array}{c}\text { (15) } \\
\text { higher }\end{array}$ \\
\hline Media use variables & & & & & \\
newspaper & $0.823^{* *}$ & $0.458^{* * *}$ & $0.622^{* * *}$ & 0.182 & 0.123 \\
radio & $0.543^{* * *}$ & $0.180^{+}$ & -0.028 & -0.153 & -0.147 \\
television & 0.168 & $0.668^{+}$ & 0.034 & -0.025 & $-0.700^{+}$ \\
internet & 0.432 & $0.591^{* * *}$ & $0.622^{* * *}$ & $0.590^{* * *}$ & $0.673^{* * *}$ \\
Control variables & & & & & \\
gender & $0.227^{+}$ & $0.237^{*}$ & $0.159^{+}$ & 0.121 & $0.405^{* * *}$ \\
age & $-0.017^{* *}$ & $-0.012^{* *}$ & $-0.007^{+}$ & $-0.011^{*}$ & $-0.011^{*}$ \\
log(income) & $0.329^{* * *}$ & $0.394^{* * *}$ & $0.314^{* * *}$ & $0.282^{* * *}$ & $0.133^{*}$ \\
party member & $0.651^{+}$ & 0.098 & $0.411^{* *}$ & -0.046 & $0.204^{+}$ \\
agriculture hukou & -0.036 & $-0.502^{* * *}$ & $-0.675^{* * *}$ & $-0.563^{* * *}$ & $-0.297^{+}$ \\
Han ethnics & 0.055 & 0.093 & 0.223 & -0.125 & 0.235 \\
year fixed effect & $-0.537^{* * *}$ & $-0.705^{* * *}$ & $-0.613^{* * *}$ & $-0.437^{* * *}$ & $-0.327^{* *}$ \\
Constant & 0.800 & 0.368 & $2.024^{* *}$ & $3.687^{* * *}$ & $6.048^{* * *}$ \\
\hline Observations & 1302 & 2647 & 3505 & 2241 & 1931
\end{tabular}




\begin{tabular}{|c|c|c|c|c|c|}
\hline $\mathrm{R}$-squared & 0.107 & 0.106 & 0.104 & 0.060 & 0.042 \\
\hline
\end{tabular}

Results in Table 3 show that, newspaper use had a positive influence on environmental knowledge when people's educational level below senior high (Model (6) - (9)), and the influence remained ( $p=.182, .0123$, respectively) when the educational level is higher (Model (10)). When media use was measured as dummy variables, the influence was positive for those below or equal to junior high education (Model (11) - (13)), but in senior high education and higher education the influence was smaller (Model (14) and (15)). Besides, it's worthy to note that, albeit the interaction item in Table 2 was not statistically significant at 0.05 level, a decreasing tendency of newspaper use's coefficient could be found in Table 3 and Table 4 as the educational level increased. Thus, it may have provided some weak evidence to support that newspaper use could offer help to decrease environmental knowledge gap.

For those below primary education, radio use exerted a positive effect on environmental knowledge (Model (6)), and that result was robust after converting the measurement (Model (11)). If the significant criterion was loosened to 0.1 , the positive effect was consistent to those who received primary education (Model (7) and (12)). However, the positive effect perished as educational level increased, the coefficient even became negative in Model (10), (13) - (15), though some of them were not statistically significant.

The effect of television use was somewhat similar with radio, though television use was not significantly in influencing environmental knowledge among low educational level people, but the coefficient is at least positive. (Model (6) - (9), (11) - (13)). However, for high educational level, the coefficient was estimated to be negative (Model (10), (14) and (15)). Especially, for those who received higher education, the statistically significant negative impact was found (Model (10)), and that result was robust under 0.1 significant level (Model (15)).

Taken together, notwithstanding the weak evidence data provided, an overall perspective could be presented that radio and television use were beneficial to environmental knowledge acquisition for those who educational level is low, but would do harm to it for those received relatively higher education.

Finally, the effects of internet use were almost inversed comparing to newspaper. The constant positive impact persisted across all educational level except for those whose educational level was below primary (Model (7) - (10)), and the results were robust as measurement was converted (Model (12)-(15)).

\section{DisCUSSION}

Based on a large and highly representative sample in China, this study investigated the influence of newspaper, radio, television and internet use on environmental knowledge gap among individuals with different educational level.

Firstly, this study took the influence of education and media use separately. Educational level was positively associated with individual's environmental knowledge, which was consistent with previous findings (Alp et.al., 2006; Zsóka et.al., 2013). That is, the more individuals were educated, the more environmental knowledge they would possess. This supported that the environmental knowledge gap did exist, and 
environmental knowledge acquisition differed across people with different educational level. In addition, this study found a positive relationship between newspaper use and environmental knowledge, as well as internet use and environmental knowledge, whereas radio and television use were more uncertain to predict environmental knowledge acquisition.

According to the empirical evidence, this study addressed knowledge gap hypothesis on environmental issues as follows. Though it seems true that more educated people were more likely to use print media as their information source (Picture 1), newspaper provided limited contribution on gaining environmental knowledge to people with higher education. However, according to heterogeneity analysis, the lower the educational level, the stronger the relationship between the use of newspaper and environmental knowledge scores. Ceiling effect may explain this tendency (Ettema \& Kline, 1977; Moore, 1987; Eveland \& Scheufele, 2000).In other words, information acquired from newspaper also followed the law of diminishing marginal utility.

As for H3b, though wasn't found any influence on knowledge in basic analysis, radio showed a positive association with environmental knowledge after interaction term was included, which suggested the previous "no effect" finding was because of positive and negative effects were counterbalanced among different educational levels. Radio did function as a knowledge lever, it helped enhance environmental knowledge acquisition of those educational level individuals and reduced the knowledge gap. This maybe because listening to audio required little literacy, thus the low educational level groups would benefit from it a lot, this could be supported by Picture 1, that less educated ones were more likely to use radio as their primary information source. As for high educational level groups, radio might not act as an effective information source but other purposes such as for entertaining. This result was different from the no effect findings in previous research (Lind \& Boomgaarden, 2019), this inconsistency might result from knowledge type.

Generally, television use was found no relationship on environmental knowledge acquisition statistically, but seemed to have a narrowing effect on knowledge gap, which partly supports H3c. However, it could not be suggested as a benefit of television use, but provided evidence that television use were harmful to individuals' knowledge. This finding was similar with the research of Ostman \& Parker (1987). Based on a survey conducted on 1984, they found that individuals' education and newspaper use brought about more environmental knowledge, concerns and behavior. However, both specific environmental information television use and general television use appeared to have negative effects. From Picture 1, it was obvious that television was almost always an important information source, thus television as a leisure media (Ruggiero, 2000) could not be attributed to the finding, the content television provided might be an underlying reason. Just as Viswanath et.al. (2006) held, newspapers were able to provide more detailed information, while television was unlikely to provide detailed information given the short time spent on each story. Television programs might not be well designed for knowledge acquisition, it might do harm to environmental knowledge level of those higher education ones because of time wasting.

As for internet use, results suggested internet widened environmental knowledge gap as H3d predicts, which was consistent with previous researches that presented internet penetration exacerbated knowledge inequalities (Yang \& Grabe, 2011; Lu \& Douglas, 2011; Kim, 2008). Two explanations, as have put in literature review, could also be addressed by this data. One is selective exposure, as Prior (2005) suggested, choosing content by oneself was a main reason leads to widening knowledge gap, and internet was an information pool where people were empowered to choose what they want. Regarding this, the measure of environmental concern ("Generally, how much do you care about environmental issues?", 5-points Likert 
scale, from "not at all" to "extremely") in CGSS 2010 might provide some insights. After deleting missing data, the sample size is 2,653. This study employed PROCESS SPSS macro (Hayes, 2012) to test the mediating effect of education to environmental knowledge, the results showed that environmental concern partially mediated the relationship between education and environmental knowledge. Regression results showed education positively predicted environmental concern $(\beta=0.033, \mathrm{p}<0.001)$, environmental concern positively predicted environmental concern $(\beta=0.242, \mathrm{p}<0.001)$, and the effect was significantly positive (indirect effect $=0.008$, BootLLCI $=[0.005,0.014]$ ). This data analysis results partly supported that, since internet is an information pool where people are empowered to select information, more educated people concern more about environmental issues, thus they are more likely to pay attention to environmental information online, gaining more environmental knowledge. The other explanation is that more educated ones are more capable of dealing with internet and the information on that, Picture 1 presented that as educational level increasing, there were larger proportion of individuals considering internet as their uppermost information source. This fact basically supported this speculation.

\section{Contributions and limitations}

Knowledge gap hypothesis is a highly conditional statement. Lind \& Boomgaarden (2019) suggested that, in knowledge gap hypothesis studies, topic, topic settings, measurements, study design, etc. were all found to have impact on the examination of knowledge gap hypothesis, whose suggestion was in line with previous researchers (Hwang and Jeong, 2009). Therefore, this study contributed to knowledge gap hypothesis in three ways: (1)This study examined knowledge gap hypothesis by a different knowledge type (environmental knowledge), aside from political knowledge (Jenssen, 2013; Kim, 2008; Lu \& Douglas, 2011), scientific knowledge (Chang et.al., 2018), and climate change knowledge (Yang, X., \& Ho, S. S., 2017). Scientific knowledge and climate change knowledge seems to be very related to general environmental knowledge, but environmental knowledge is more specific than scientific knowledge and broader than climate change knowledge. Therefore, this study provided different perspectives to present knowledge gap hypothesis studies.

(2) This study used heterogeneity analysis to provide a more detailed and profound understanding to the relationship between media use and environmental knowledge gap, which to our limited knowledge hasn't been conducted in knowledge gap hypothesis studies. (3) This study offered empirical evidence to knowledge gap hypothesis by using a highly representative data in China. To our limited knowledge, little literature has tested knowledge gap hypothesis on environmental issues in China before, this study provided alternative insights into this hypothesis in a new context. (4) Past studies often use specific information attention (such as scientific news attention and political news attention) as the measurement of media use; therefore, they avoid the potential effect of selective exposure. While this study applied general media use variables in the model, which is closer to the original view of knowledge gap hypothesis.

This study is not without limitations. Although the sample size is large and representative, two problems remain about the data. (1) The data is secondary, which limits the refinement of the measurement. (2) The data was collected during 2010-2013. Nowadays, the usage of media has been shifting from traditional media to online media. However, though the use of traditional media is gradually diminishing, the formats of media content (e.g., video, audio streaming, and text) are similar nowadays. Therefore, the insights of this study in knowledge gap hypothesis are still valuable. Future study should investigate knowledge gap hypothesis by considering updated patterns of media use to compare with the existing findings. 


\section{Reference}

Aldy, J. E., Orszag, P. R., \& Stiglitz, J. E. (2001, October). Climate change: an agenda for global collective action. In Prepared for the conference on the timing of climate Change policies, Pew Center on Global Climate Change, Washington, DC.

Alp, E., Ertepinar, H., Tekkaya, C., \& Yilmaz, A. (2006). A statistical analysis of children's environmental knowledge and attitudes in Turkey. International Research in Geographical and Environmental Education, 15(3), 210-223.

Bessinger, R., Katende, C., \& Gupta, N. (2004). Multi-media campaign exposure effects on knowledge and use of condoms for STI and HIV/AIDS prevention in Uganda. Evaluation and Program Planning, 27(4), 397-407.

Boykoff, M. T. (2011). Who speaks for the climate?: Making sense of media reporting on climate change. Cambridge University Press.

Brothers, C. C., Fortner, R. W., \& Mayer, V. J. (1991). The impact of television news on public environmental knowledge. The Journal of Environmental Education, 22(4), 22-29.

Carmi, N., Arnon, S., \& Orion, N. (2015). Transforming environmental knowledge into behavior: The mediating role of environmental emotions. The Journal of Environmental Education, 46(3), 183-201.

Chan, K. K. (1998). Mass media and environmental knowledge of secondary school students in Hong Kong. Environmentalist, 19(2), 85-97.

Chang, J. H., Kim, S. H., Kang, M. H., Shim, J. C., \& Ma, D. H. (2018). The gap in scientific knowledge and role of science communication in South Korea. Public Understanding of Science, 27(5), 578-593.

Cheng, T. M., \& Wu, H. C. (2015). How do environmental knowledge, environmental sensitivity, and place attachment affect environmentally responsible behavior? An integrated approach for sustainable island tourism. Journal of Sustainable Tourism, 23(4), 557-576.

Communiqué on Major Data of the Sixth National Census in 2010 (No. 1) [In Chinese]. (n.d.). Retrieved September 12, 2020, from http://www.stats.gov.cn/tjsj/tjgb/rkpcgb/qgrkpcgb/201104/t20110428_30327.html

Culbertson, H. M., \& STEMPEL III, G. H. (1986). How media use and reliance affect knowledge level. Communication Research, 13(4), 579-602.

Eden, S. (1998). Environmental issues: knowledge, uncertainty and the environment. Progress in Human Geography, 22(3), 425-432.

Ettema, J. S., \& Kline, F. G. (1977). Deficits, differences, and ceilings: Contingent conditions for understanding the knowledge gap. Communication research, 4(2), 179-202. 
Eveland Jr, W. P. (2001). The cognitive mediation model of learning from the news: Evidence from nonelection, off-year election, and presidential election contexts. Communication Research, 28(5), 571601.

Eveland Jr, W. P., \& Scheufele, D. A. (2000). Connecting news media use with gaps in knowledge and participation. Political communication, 17(3), 215-237.

Frick, J., Kaiser, F. G., \& Wilson, M. (2004). Environmental knowledge and conservation behavior: Exploring prevalence and structure in a representative sample. Personality and Individual differences, 37(8), 15971613.

Fryxell, G. E., \& Lo, C. W. (2003). The influence of environmental knowledge and values on managerial behaviours on behalf of the environment: An empirical examination of managers in China. Journal of business ethics, 46(1), 45-69.

Gaziano, C. (1983). The knowledge gap: An analytical review of media effects. Communication research, 10(4), 447-486.

Hansen, A. (2011). Communication, media and environment: Towards reconnecting research on the production, content and social implications of environmental communication. International Communication Gazette, 73(1-2), 7-25. https://doi.org/10.1177/1748048510386739

Hargittai, E., \& Hinnant, A. (2008). Digital inequality: Differences in young adults' use of the Internet. Communication research, 35(5), 602-621.

Hayes, A. F. (2012). PROCESS: A versatile computational tool for observed variable mediation, moderation, and conditional process modeling.

Hew, K. F. (2009). Use of audio podcast in K-12 and higher education: A review of research topics and methodologies. Educational Technology Research and Development, 57(3), 333-357.

Hwang, Y., \& Jeong, S. H. (2009). Revisiting the knowledge gap hypothesis: A meta-analysis of thirty-five years of research. Journalism \& Mass Communication Quarterly, 86(3), 513-532.

Jenssen, A. T. (2013). Widening or closing the knowledge gap?. Nordicom Review, 33(1), 19-36.

Katz, E., Haas, H., \& Gurevitch, M. (1973). On the use of the mass media for important things. American sociological review, 164-181.

Katz, E., Haas, H., \& Gurevitch, M. (1973). On the use of the mass media for important things. American sociological review, 164-181.

Kim, S. H. (2008). Testing the knowledge gap hypothesis in South Korea: Traditional news media, the Internet, and political learning. International Journal of Public Opinion Research, 20(2), 193-210. 
Kwak, N. (1999). Revisiting the knowledge gap hypothesis: Education, motivation, and media use. Communication Research, 26(4), 385-413.

Laurian, L. (2003). A prerequisite for participation: Environmental knowledge and what residents know about local toxic sites. Journal of Planning Education and Research, 22(3), 257-269.

Lind, F., \& Boomgaarden, H. G. (2019). What we do and don't know: A meta-analysis of the knowledge gap hypothesis. Annals of the International Communication Association, 43(3), 210-224.

Lu Wei \& Douglas Blanks Hindman (2011) Does the Digital Divide Matter More? Comparing the Effects of New Media and Old Media Use on the Education Based Knowledge Gap, Mass Communication and Society, 14:2, 216-235

Moore, D. W. (1987). Political campaigns and the knowledge-gap hypothesis. Public Opinion Quarterly, 51(2), 186-200.

Nelkin, D. (1987). Selling science: How the press covers science and technology. New York, NY: Freeman.

Nguyen, B., Yu, X., Melewar, T. C., \& Chen, J. (2015). Brand innovation and social media: Knowledge acquisition from social media, market orientation, and the moderating role of social media strategic capability. Industrial Marketing Management, 51, 11-25.

Ostman, R. E., \& Parker, J. L. (1987). Impact of education, age, newspapers, and television on environmental knowledge, concerns, and behaviors. The Journal of Environmental Education, 19(1), 3-9.

Prior, M. (2005). News vs. entertainment: How increasing media choice widens gaps in political knowledge and turnout. American Journal of Political Science, 49(3), 577-592.

Robelia, B., \& Murphy, T. (2012). What do people know about key environmental issues? A review of environmental knowledge surveys. Environmental Education Research, 18(3), 299-321.

Ruggiero, T. E. (2000). Uses and gratifications theory in the 21st century. Mass communication \& society, 3(1), 3-37.

Stamm, K. R., Clark, F., \& Eblacas, P. R. (2000). Mass communication and public understanding of environmental problems: the case of global warming. Public understanding of science, 9(3), 219-238.

Su, L. Y. F., Cacciatore, M. A., Scheufele, D. A., Brossard, D., \& Xenos, M. A. (2014). Inequalities in scientific understanding: Differentiating between factual and perceived knowledge gaps. Science Communication, 36(3), 352-378.

Tewksbury, D., \& Althaus, S. L. (2000). Differences in knowledge acquisition among readers of the paper and online versions of a national newspaper. Journalism \& Mass Communication Quarterly, 77(3), 457-479.

Tichenor, P. J., Donohue, G. A., \& Olien, C. N. (1970). Mass media flow and differential growth in knowledge. Public opinion quarterly, 34(2), 159-170. 
Valkenburg, P. M., \& Peter, J. (2013). Comm Research—Views from Europe| Five Challenges for the Future of Media-Effects Research. International Journal of Communication, 7, 19.

Vicente-Molina, M. A., Fernández-Sáinz, A., \& Izagirre-Olaizola, J. (2013). Environmental knowledge and other variables affecting pro-environmental behaviour: comparison of university students from emerging and advanced countries. Journal of Cleaner Production, 61, 130-138.

Viswanath, K., \& Finnegan Jr, J. R. (1996). The knowledge gap hypothesis: Twenty-five years later. Annals of the International Communication Association, 19(1), 187-228.

Viswanath, K., Breen, N., Meissner, H., Moser, R. P., Hesse, B., Steele, W. R., \& Rakowski, W. (2006).

Cancer knowledge and disparities in the information age. Journal of health communication, 11(S1), 1-17.

Wade, S., \& Schramm, W. (1969). The mass media as sources of public affairs, science, and health knowledge. Public Opinion Quarterly, 33(2), 197-209.

Yang, J., \& Grabe, M. E. (2011). Knowledge acquisition gaps: A comparison of print versus online news sources. New Media \& Society, 13(8), 1211-1227.

Yang, X., \& Ho, S. S. (2017). Decreasing the knowledge gap among different socioeconomic status groups on the issue of climate change. Environmental Hazards, 16(3), 276-290.

Zhao, X. (2009). Media use and global warming perceptions: A snapshot of the reinforcing spirals. Communication Research, 36(5), 698-723.

Zsóka, Á., Szerényi, Z. M., Széchy, A., \& Kocsis, T. (2013). Greening due to environmental education? Environmental knowledge, attitudes, consumer behavior and everyday pro-environmental activities of Hungarian high school and university students. Journal of Cleaner Production, 48, 126-138. 